\begin{tabular}{ll}
\hline ISSN: 1410-8917 & Jurnal Kimia Sains dan Aplikasi 23 (6) (2020): 189-195 \\
Jurnal Kimia & Jurnal Kimia Sains dan Aplikasi \\
Aplikasi & Journal of Scientific and Applied Chemistry \\
\hline
\end{tabular}

\title{
Prediction of Pharmacokinetics Parameter and Molecular Docking Study of Antidiabetic Compounds from Syzygium polyanthum and Syzygium cumini
}

\author{
Widia Wati ${ }^{\mathrm{a}, 1}$, Gunawan Pamudji Widodo ${ }^{\mathrm{a}, 2}$, Rina Herowati ${ }^{\mathrm{a}, 3,{ }^{*}}$ \\ ${ }^{\text {a }}$ Faculty of Pharmacy, Setia Budi University, Surakarta 57127, Indonesia
}

Authors emails: (1)widiawty.236@gmail.com; (2) gunawanpamudji@yahoo.com; (3,*) rinagunawan53@gmail.com

https://doi.org/10.14710/jksa.23.6.189-195

\section{Article Info}

Article history:

Received: $8^{\text {th }}$ December 2019

Revised: $21^{\text {st }}$ May 2020

Accepted: $31^{\text {st }}$ May 2020

Online: $30^{\text {th }}$ June 2020

Keywords:

molecular docking;

Syzygium polyanthum;

Syzygium cumini;

antidiabetic; AutoDock

Vina; SwissADME

\begin{abstract}
Syzygium polyanthum leaf extract and Syzygium cumini herbs extract have been reported to have antidiabetic activity. This study aimed to predict the molecular target of chemical constituents of S. polyanthum and S. cumini as well as study their interactions with various macromolecular targets of an antidiabetic agent. Molecular docking of all ligands was studied using the Autodock Vina program in PyRx, and the results are presented as binding affinity values ( $\mathrm{kcal} / \mathrm{mol}$ ) of ligand against the protein. PyMOL is used to visualize the $3 \mathrm{D}$ molecular of docked conformation and ligand-protein interactions. The predicted pharmacokinetic parameters were obtained by SwissADME. Delphinidin-3-gentiobioside and isoquercitrin are predicted to have good interaction with DPP- 4 and $\alpha$-glucosidase, respectively. However, they are predicted to have poor absorption properties. Quercetin and kaempferol are predicted to have good interaction with PTP1B and glucokinase and showed good pharmacokinetic properties.
\end{abstract}

\section{Introduction}

Diabetes mellitus (DM) is a condition in which blood glucose is too high. DM occurs if the body does not produce or the amount of insulin is insufficient to induce the conversion of glucose to glycogen, causing glucose to accumulates in the blood. The most common classifications include type $1 \mathrm{DM}$ (caused by an absolute or near-absolute insulin deficiency), type $2 \mathrm{DM}$ (characterized by the presence of insulin resistance with a small compensatory increase in insulin secretion), and gestational diabetes (developed during pregnancy) [1]. Type 2 DM is more commonly found since it is related to diet and lifestyle. Oral antidiabetic drugs have different molecular targets (sulfonylureas, thiazolidinedione, biguanide, insulin receptor sensitizer, and $\alpha$ glucosidase inhibitor). These medicines generally work to increase insulin secretion and receptor sensitivity. However, long-term use often poses problems, especially side effects, which also have an impact on lowering patient compliance [2].

Some target molecules related to DM molecules are $\alpha$-glucosidase, glucokinase, dipeptidyl-peptidase 4
(DPP4), and protein tyrosine phosphatase-1B (PTP1B) [3]. $\alpha$-glucosidase is a member of the glycoside hydrolase enzyme that cuts the glycosidic bond of carbohydrate, leading to the elevation of blood glucose levels [4]. Glucokinase is an enzyme that serves to phosphorylate glucose; this enzyme deficiency can cause type $2 \mathrm{DM}$ at an early age [3]. DPP-4 is an enzyme that hydrolyzes Glucagon-Like Peptide-1 (GLP-1) so that GLP-1 becomes inactive. GLP-1 plays a role in the body's metabolism, including insulin secretion, increase $\beta$ cell mass, glucagon secretion, and reduction in gastric discharge [5]. High expression of PTP1B affects the activity of the tyrosine kinase protein substrate resulting in insulin failure to join insulin receptors, induces insulin resistance, and causes type 2 DM [6].

Herbal medicine is one of the many alternatives used to treat diabetes mellitus. Many traditional medicines have been proven potential as antidiabetic, including plants from the Myrtaceae family. Syzygium polyanthum and Syzygium cumini are examples of plants belonging to the Myrtaceae family. Lelono and Tachibana [7] reported that S. polyanthum extract showed 
potential antidiabetic activity through $\alpha$-glucosidase inhibition with an $\mathrm{IC}_{50}$ value of methanol-water extract, methanol extract, and a water extract of 70.90, 91.52, and $72.72 \mu \mathrm{g} / \mathrm{mL}$, respectively. Rahim et al. [8] using GCMS analysis showed that $S$. polyanthum leaves contain linalool (in $n$-hexane and ethyl acetate extracts) and $\beta$ cytoosterol (in $n$-hexane, ethyl acetate, and methanol extracts) which are potential as antidiabetic agents. Ethanol extract of S. cumini showed a significant decrease in blood glucose levels, probably by stimulating insulin secretagogue activity and increasing glycogen storage in normal rat muscles [9]. Ramya et al. [10] reported that $S$. cumini contains many chemical compounds that play a role in an antidiabetic activity, such as anthocyanins, bergenins, citric acid, caffeic acid, cinnamaldehyde, ßsitosterol, and so forth.

Computer-Aided Drug Design (CADD) uses computational approaches to discover, develop, and analyze drugs or pharmacologically active molecules. Molecular docking, one of CADD, provides advantages in the discovery and development of new drugs and can help make cost-effective decisions before the costly process of drug synthesis begins [11]. Molecular docking involves conformation and orientation of ligand (small molecule) in the binding site of the target protein. One of the parameters evaluated in molecular docking is affinity, a measure of the ability of a compound to interact with its target protein. The introduction of macromolecule targets and the mechanism of action of active compounds can facilitate the optimization of activities. If the target work of a compound in providing a pharmacological effect is known, further optimization of drug activity is directed based on the drug-targeted interaction pattern [12].

Another critical step in drug discovery and development is the prediction of pharmacokinetic parameters. After administering the drug, the drug will be distributed throughout the body based on various factors that can eliminate, damage, or prevent it from reaching the therapeutic target. The influencing factors are absorption, distribution, metabolism, and excretion (ADME), which are called pharmacokinetics. The computer approaches have been developed as an alternative to experimental procedures for the prediction of ADME, especially at the initial step. SwissADME is a web tool that provides free access to predict the physicochemical properties, pharmacokinetics, druglikeness, and medicinal chemistry friendliness of small molecules [13].

This research was conducted to determine the chemical compounds of $S$. polyanthum and $S$. cumini herbs that potentially influence antidiabetic molecular targets, i.e., $\alpha$-glucosidase, glucokinase, DPP-4, as well as PTP1B by molecular docking analysis, and predict the pharmacokinetic properties (ADME) of potentially active compounds.

\section{Methodology}

\subsection{Equipment}

Hardware that we used in this study was desktop with specification Processor Intel $1^{\circledR}$ Core $^{\mathrm{TM}}$ i7-3770 @3.40 GHz, $8 \mathrm{~Gb}$ RAM. Installed software that we used was MarvinSketch, PyRx 0.8 [14], VegaZZ [15], Discovery Studio Visualizer [16], AutoDock 4.0 [17], and PyMOL Educational (Schrodinger) [18]. SwissADME web tool was used to predict the ADME properties of potentially active compounds [13].

\subsection{Ligand preparation}

Forty-one compounds of S. polyanthum and 40 compounds of $S$. cumini were obtained from a literature search. The SMILES of each compound were searched using Pubchem (https//pubchem.ncbi.nlm.nih.gov/). The SMILES from each compound were pasted into Marvinsketch to generate a two-dimensional structure, then saved as MOL file format. The mol file format was converted to a three-dimensional structure using VegaZZ and saved as a PDB file format [15]. The PDB file format was opened by PyRx 0.8. Menu "Load molecule" and "selected make ligand" were clicked, then was saved as PDBQT file format.

\subsection{Protein structure preparation}

Protein structures of macromolecular targets were downloaded from RCSB Protein Data Bank in PDB file format, i.e., DPP-4 (PDB ID 2QOE), PTP1B (PDB ID 5T19), glucokinase (PDB ID 4RCH), and $\alpha$-glucosidase (PDB ID 5NN8) $[14,15,16]$. AutoDock Tools conducted protein structure preparation. Water molecules and all nonstandard residues were removed from the initial structure. Then, all missing hydrogens and Kollman charges were added to the system. The prepared target proteins were then saved as a PDBQT file format.

\subsection{Docking validation}

Docking validation was performed for all proteins target docking simulation. The native ligand was extracted from pdb complex, then prepared in the same way as the test ligand using PyRx 0.8. The prepared native ligand then was 'redocked' to its target protein. The grid center was placed approximately to the center of the ligand, covering all the binding site residues. Validation was confirmed to be valid if the RMSD value of redocked and crystallography ligand was less than $2 \AA$ [19].

\subsection{Molecular docking analysis with autodock vina in PyRx}

Forty-one compounds of S. polyanthum and 40 compounds of S. cumini were docked to four molecular targets to study their free binding energy and intermolecular interaction. This docking simulation used the same method, grid size and grid center, and exhaustiveness number as was done in the previously validated procedure [17]. 


\subsection{Visualization}

PyMOL and Discovery Studio Visualizer were used to visualize the docking result. PyMOL was used for RMSD calculation, while Discovery Studio Visualizer was used to analyze intermolecular interaction in twodimensional space [18].

\subsection{Prediction of ADME Properties}

Prediction of ADME properties was conducted using the SwissADME web tool (http//www.swissadme.ch) by entering the SMILES list of chemical compounds. The predicted parameters were Lipinski's rules, bioavailability, BBB permeant, GI absorption, P-gp substrate, and metabolic enzyme inhibition [13].

\section{Results and Discussion}

\subsection{Docking validation}

Docking validation aims to establish the validity of the docking method by calculating the deviation of the redocking result compared to original $3 \mathrm{D}$ ligand conformation to the target protein. It is indicated as Root Mean Square Deviation (RMSD). The docking method is declared valid if the RMSD value is less than $2 \AA$ [20]. The docking validation results show that the RMSD value of all protein targets is less than $2 \AA$. Thus, docking method that used in this study is valid. The results of docking validation are described in Figure 1.
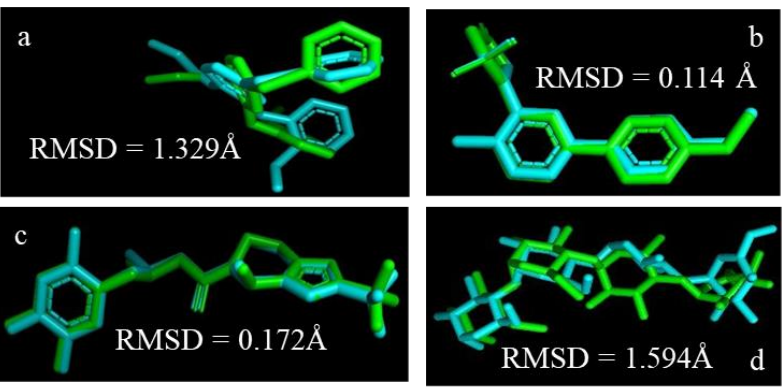

Figure 1. RMSD of superimposed redocked native ligand (cyan) and crystallographic (green). (A) glucokinase (4RCH) ; (B) protein tyrosine phosphatase-1B (5T19) ; (C) dipeptidyl peptidase-4 (2QOE) ; (D) $\alpha$-glucosidase (5NN8).

\subsection{Molecular docking}

Docking simulations were carried out using AutoDock Vina in PyRx 0.8. Molecular docking aims to characterize the interaction of small molecules in the binding site of target proteins as well as to elucidate fundamental biochemical processes. Table 1 presents three compounds in S. polyanthum and S. cumini with the lowest binding energy values for each target protein, indicating an excellent affinity. Delphinidin-3gentiobioside from $S$. cumini shows the best affinity to DPP- 4 as well as $\alpha$-glucosidase. Ellagic acid and kaempferol show the best affinity to PTP1B and glucokinase, respectively. All compounds from $S$. polyanthum exhibit low affinity to DPP-4, glucokinase as well as $\alpha$-glucosidase. However, squalene exhibits the best affinity for glucokinase.
Table 1. Binding energy values of three best compounds to each target protein

\begin{tabular}{|c|c|c|c|}
\hline Target Protein & Sources & Chemical compounds & $\begin{array}{l}\text { Binding } \\
\text { energy } \\
(\mathrm{kcal} / \mathrm{mol})\end{array}$ \\
\hline \multirow[t]{7}{*}{ DPP-4 } & Native ligand & Triazolopiperazine & $-8.3 \pm 0.29$ \\
\hline & S. cumini & $\begin{array}{l}\text { Delphinidin-3- } \\
\text { gentiobioside }\end{array}$ & $-9.5 \pm 0.05$ \\
\hline & & Myricetin & $-9.2 \pm 0.00$ \\
\hline & & Quercetin & $-8.7 \pm 0.00$ \\
\hline & S. polyanthum & $\begin{array}{c}\text { Isopropenyl-4a,8- } \\
\text { dimethyl-1,2,3,4,4a,5,6,7- } \\
\text { octahydronaphtha lene }\end{array}$ & $-6.9 \pm 0.00$ \\
\hline & & $\beta$-cubebene & $-6.9 \pm 0.00$ \\
\hline & & Valencene & $-6.9 \pm 0.06$ \\
\hline \multirow[t]{7}{*}{ PTP1B } & Native ligand & $\begin{array}{c}\text { N-(3'-(1,1-dioxido-4- } \\
\text { oxo-1,2,5-thiadiazolidin- } \\
\text { 2yl)-4'-methyl-[1,1'- } \\
\text { biphenyl]-4-yl) } \\
\text { acetamide. }\end{array}$ & $-9.6 \pm 1.00$ \\
\hline & S. cumini & Ellagic acid & $-9.2 \pm 0.00$ \\
\hline & & Myricetin & $-9.0 \pm 0.06$ \\
\hline & & Quercetin & $-9.1 \pm 0.00$ \\
\hline & S. polyanthum & $\delta$-cadinene & $-8.0 \pm 0.00$ \\
\hline & & $\begin{array}{c}\text { Isopropenyl-4a,8- } \\
\text { dimethyl-1,2,3,4,4a,5,6,7- } \\
\text { octahydronaphtha lene }\end{array}$ & $-7.7 \pm 0.25$ \\
\hline & & $\beta$-cubebene & $-7.7 \pm 0.30$ \\
\hline \multirow[t]{7}{*}{ Glucokinase } & Native ligand & 2-pyridyl urea & $-8.3 \pm 0.08$ \\
\hline & S. cumini & Kaempferol & $-9.0 \pm 0.00$ \\
\hline & & $\begin{array}{l}\text { Delphinidin-3- } \\
\text { gentiobioside }\end{array}$ & $-8.9 \pm 0.05$ \\
\hline & & Quercetin & $-8.8 \pm 0.05$ \\
\hline & S. polyanthum & Squalene & $-9.1 \pm 0.13$ \\
\hline & & $\beta$-tocopherol & $-8.9 \pm 0.00$ \\
\hline & & $\gamma$-tocopherol & $-8.7 \pm 0.14$ \\
\hline \multirow[t]{7}{*}{$\alpha$-glucosidase } & Native ligand & Acarbose & $-8.4 \pm 0.05$ \\
\hline & S. cumini & $\begin{array}{l}\text { Delphinidin-3- } \\
\text { gentiobioside }\end{array}$ & $-8.5 \pm 0.00$ \\
\hline & & Isoquercitrin & $-8.5 \pm 0.00$ \\
\hline & & Acetyl oleanolic acid & $-7.7 \pm 0.04$ \\
\hline & S. polyanthum & $\alpha$-cubebene & $-7.0 \pm 0.00$ \\
\hline & & $\beta$-tocopherol & $-7,0 \pm 0.11$ \\
\hline & & $\begin{array}{c}\text { Isopropenyl-4a,8- } \\
\text { dimethyl-1,2,3,4,4a,5,6,7- } \\
\text { octahydronaphthalene }\end{array}$ & $-6.9 \pm 0.05$ \\
\hline
\end{tabular}

*Bold font indicates lower binding energy value than the native ligand

\subsection{Model of interaction}

Visualization of interaction between compounds with the best affinity and target protein was conducted using PyMOL and Discovery Studio Visualizer. The amino acids involved in interaction and the type of chemical bond were compared between the best compounds in table 1 and the native ligand of each target protein, to analyze the similarity of the interaction model. Analysis of interaction model reveals that the compounds with good affinity and model interaction similar to the native ligand were delphinidin-3-gentiobioside (for DPP-4), quercetin (for PTP1B), kaempferol (for glucokinase), and isoquercitrin (for $\alpha$-glucosidase).

Figure $2 \mathrm{~A}$ represents the interaction between the native ligand (triazolopiperazine) to the binding pocket of DPP-4. Kowalchick et al. [20] reported that 2,4,5trifluorophenyl moiety of triazolopiperazine occupied 
the hydrophobic pocket in the DPP- 4 enzyme, while the (R)-b-amino group interacts with glutamate residues (Glu205 and Glu206) through four hydrogen-bonding interactions. A water molecule connects the nitrogen atoms of the triazolopiperazine and the carboxylic oxygen and the hydroxyl of Tyr547. Interactions also occur between a molecule of triazolopiperazine and amino acid residues (Phe357 and Arg125). Delphinidin3-gentiobioside exhibits similar interactions with the binding pocket of DPP-4. Hydrogen bonding occurs between delphinidin-3-gentiobioside to Glu205, Tyr662, as well as Arg125 (Figure 2B).

Figure $3 \mathrm{~A}$ represents the interaction between the native ligand (N-(3)-(1,1-dioxido-4-oxo-1,2,5thiadiazolidin-2yl)-4'-methyl-[1,1'-biphenyl]-4yl)acetamide) to the binding pocket of PTP1B. Punthasee et al. [21] reported that hydrogen bonding occurs between sulfone oxygens and Arg221, while the 1,2,5thiadiazolidin-3-one 1,1-dioxide ring is fully occupied the loop consisting of residues 216-220. The carbonyl oxygen of this ring hydrogen-bonded to Phe182 and Gln266. The methylene residues of the heterocycle and aromatic rings of the biphenyl group interacting with aromatic and nonpolar residues are Tyr46, Val49, Ala217, Ile219, and Phe182. Quercetin interacts with the binding pocket of PTP1B in a similar pattern as the native ligand. Hydrogen bonds occur between the catechol group and Arg221, Ser216, and Ala217. This result is supported by the previous report that quercetin shows a potential PTP1B inhibitory activity, with the $\mathrm{IC}_{50}$ value of $200 \mu M[22]$.

Figure $4 \mathrm{~A}$ represents the interaction between the native ligand (2-pyridyl urea) to the binding pocket of glucokinase. Hinklin et al. [23] reported that hydrogen bonds occur between the urea group and Arg63, while ethyl pyridyl ether on the 3-position of the pyridyl core forms hydrophobic interaction with several hydrophobic residues (including Ser64). Thiopyridyl group in 5position also fully occupies the hydrophobic cavity by interacting with Ile211 and Tyr214. Hydrophobic interactions are also seen in kaempferol with hydrophobic residues. However, hydrogen bonding occurs with Tyr215, different from the native ligand (Arg63).

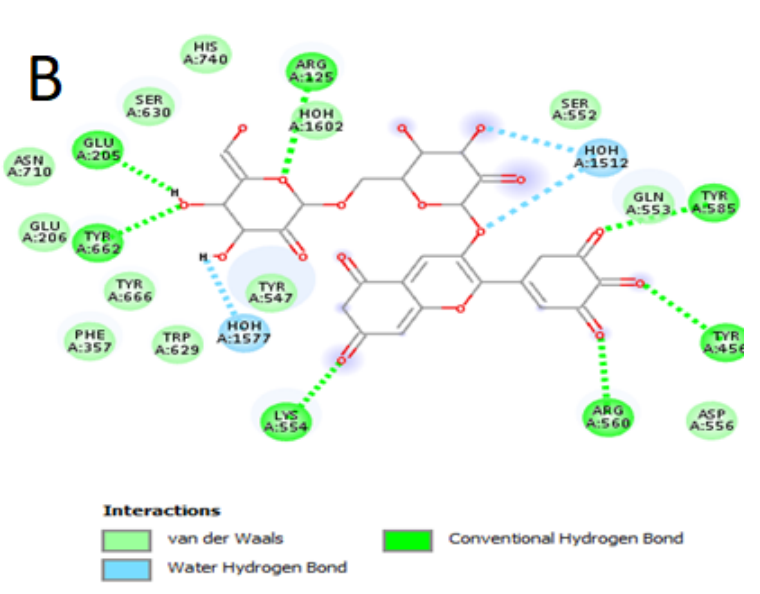

Figure 2. Model interaction of native ligand (A) and delphinidin-3-gentiobioside (B) to DPP-4 (created by Discovery Studio Visualizer)
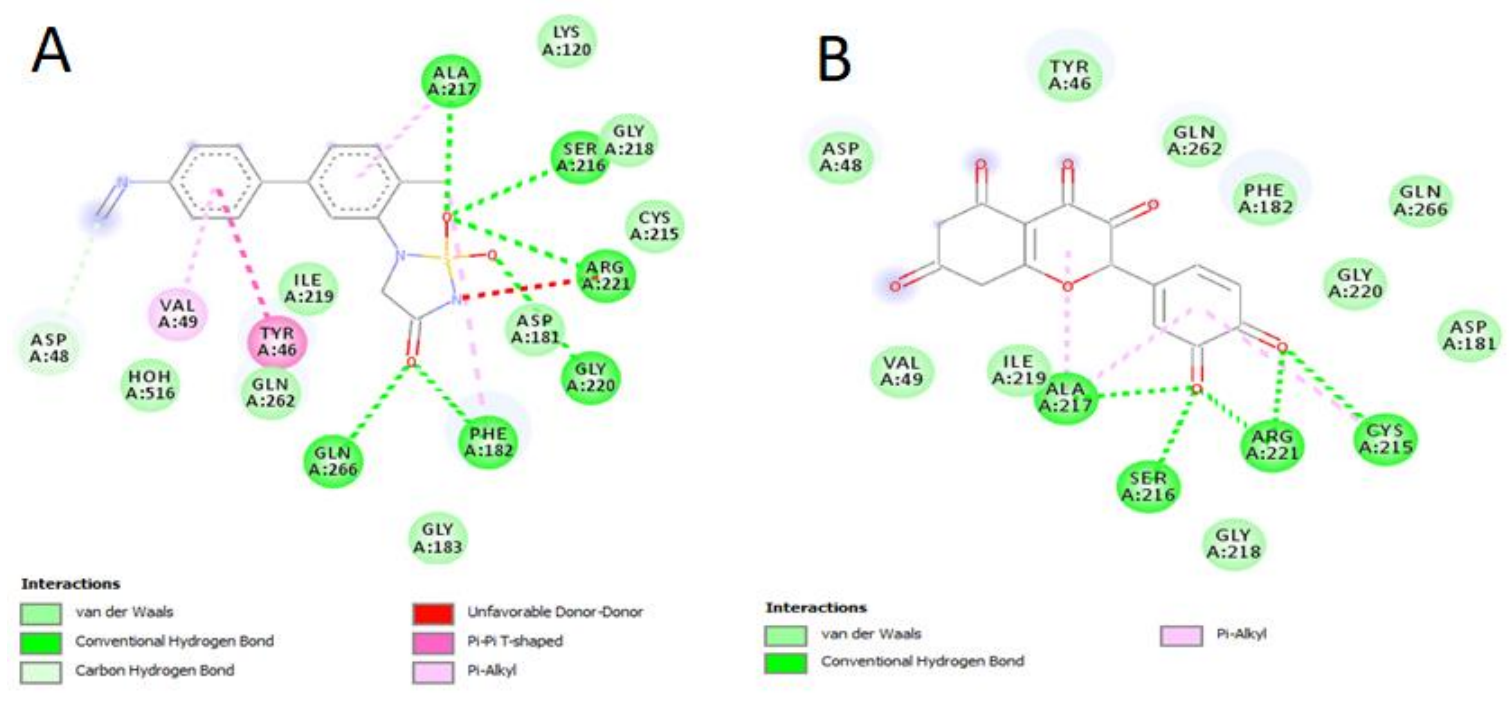

Figure 3. Model interaction of native ligand (A) and quercetin (B) to PTP1B (created by Discovery Studio Visualizer) 


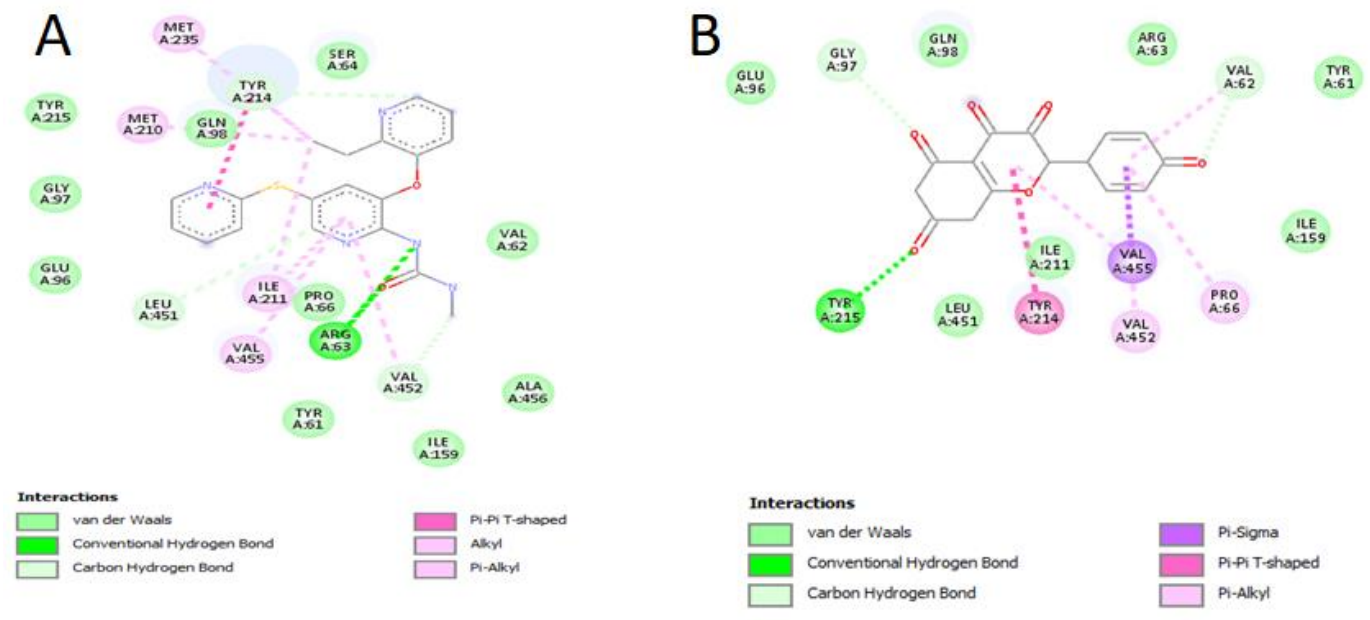

Figure 4. Model interaction of native ligand (A) and kaempferol (B) to glucokinase (created by Discovery Studio Visualizer)
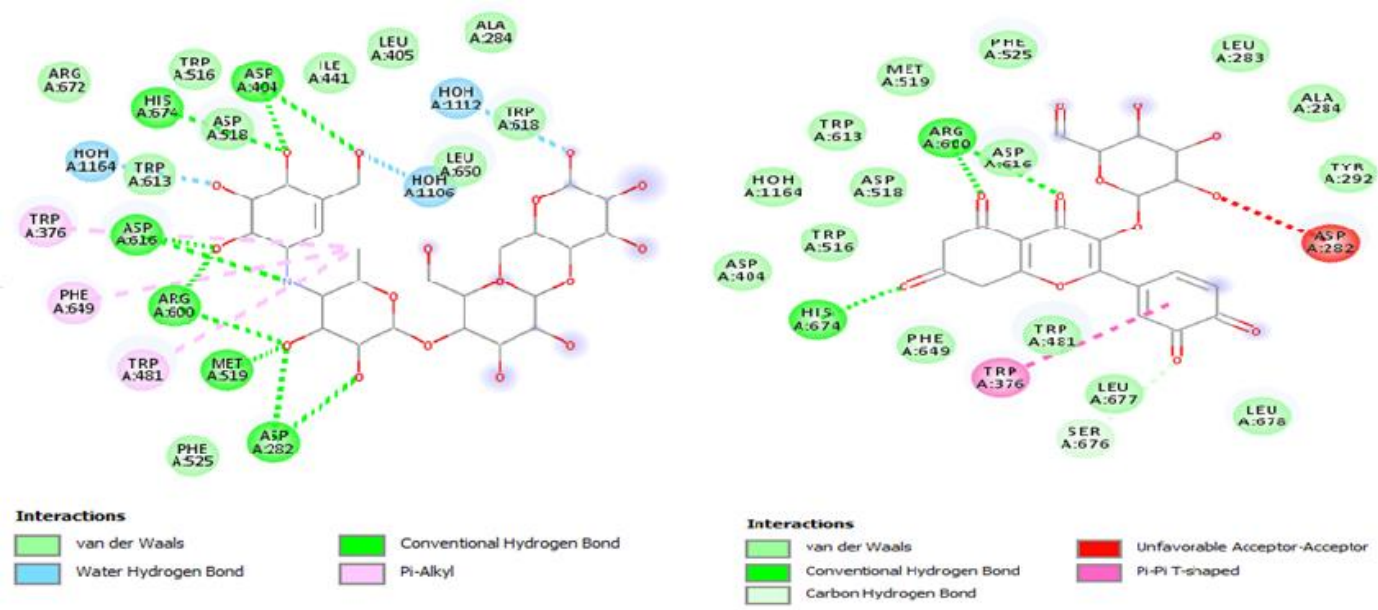

Figure 5. Model interaction of native ligand (A) and isoquercitrin (B) to $\alpha$-glucosidase (created by Discovery Studio Visualizer)

Table 2. Interaction between ligands and the target proteins

\begin{tabular}{|c|c|c|}
\hline $\begin{array}{l}\text { Target } \\
\text { Protein }\end{array}$ & Chemicals Compounds & Amino acid residues involved in the interaction \\
\hline \multirow[t]{3}{*}{ DPP-4 } & Native ligand & Glu206A, Glu205A, Tyr662A, Phe357A \\
\hline & $\begin{array}{l}\text { Delphinidin-3- } \\
\text { gentiobioside }\end{array}$ & $\begin{array}{l}\text { His740A, Ser630A, Asn710A, Glu206A, Glu205A, Tyr662A, Tyr666A, Phe357A, Trp629A, Tyr547A, Lys554A, Ser552A, } \\
\text { Gln553A, Tyr585A, Tyr456A, Arg560A, Asp556A }\end{array}$ \\
\hline & Myricetin & $\begin{array}{c}\text { Ser209A, Glu206A, Arg669A, Tyr547A, Tyr666A, Glu205A, Tyr631A, Tyr662A, Phe357A, Val711A, Arg125A, Ser630A, } \\
\text { Asn710A, His740A }\end{array}$ \\
\hline \multirow[t]{4}{*}{ PTP1B } & Native ligand & Gln266A, Gly220A, Ala217A, Arg221A, Ser216A, Tyr46A, Phe182A, Gln262A \\
\hline & Ellagic acid & Val49A, Ile219A, Asp181A, Lys120A, Gly220A, Ala217A, Arg221A, Ser216A, Tyr46A, Phe182A, Gln262A, Cys215A \\
\hline & Quercetin & $\begin{array}{l}\text { Asp48A, Ile219, Val49A, Gln266A, Gly220A, Ala217A, Arg221A, Ser216A, Tyr46A, Phe182A, Gln262A, Cys215A, } \\
\text { Asp181A. }\end{array}$ \\
\hline & Myricetin & $\begin{array}{c}\text { Asp48A, Gly218A, Ile219A, Val49A, Gln266A, Gly220A, Ala217A, Arg221A, Ser216A, Tyr46A, Phe182A, Gln262A, } \\
\text { Cys215A }\end{array}$ \\
\hline \multirow[t]{3}{*}{ Glucokinase } & Native Ligand & Tyr214A, Ile211A, Ser64A, Arg63A \\
\hline & Kaempferol & $\begin{array}{c}\text { Glu96A, Gly97A, Gln98A, Tyr214A, Ile211A, Ser64A, Arg63A, Val62A, Pro66A, Val455A, Val452A, Leu451A, Tyr215A, } \\
\text { Tyr61A, Ile159A }\end{array}$ \\
\hline & Squalene & $\begin{array}{l}\text { Lys459A, Ile159A, Ala456A, Pro66A, Gly97A, Glu96A, His218A, Gln98A, Leu451A, Tyr215A, Tyr61A, Val62A, Tyr214A, } \\
\text { Ile211A, Ser64A, Arg63A, Val452A, Val455A, Glu67A, Met235A }\end{array}$ \\
\hline \multirow{3}{*}{$\begin{array}{c}\alpha- \\
\text { glucosidase }\end{array}$} & Native Ligand & Asp404A, His674A, Asp616A, Arg600A, Asp282A \\
\hline & $\begin{array}{l}\text { Delphinidin-3- } \\
\text { gentiobioside }\end{array}$ & $\begin{array}{c}\text { Ala555A, Asn524A, Phe525A, Ser523A, Asp282A, Met519A, Arg600A, Asp616A, Trp481, Leu283A, Arg281A, Leu677A, } \\
\text { Ser676A, Leu678A, Tyr292A, Ala284A, Phe649A, Leu650A, Gly651A }\end{array}$ \\
\hline & Isoquercetin & $\begin{array}{c}\text { Asp404A, Trp613A, Trp518A, Met519A, Phe525A, Arg60oA, Trp516A, Asp616A, His674A, Phe649A, Trp481A, } \\
\text { Trp376A, Leu677A, Ser676A, Leu283A, Leu678A, Ala284A, Tyr292A, Asp282A }\end{array}$ \\
\hline
\end{tabular}

*Bold font indicated the amino acid residues same as native ligand 
Figure $5 \mathrm{~A}$ presents the interaction between the native ligand (acarbose) to the binding pocket of $\alpha$ glucosidase. Roig-Zamboni et al. [24] reported that stable interactions occur through hydrogen bonds with side chains Asp282, Asp404, Asp518, Arg600, Asp616, and His674. Isoquercitrin interacts with two amino acid residues of $\alpha$-glucosidase, which are the same as the native ligands, i.e., Asp616, Arg600, and His674. This result is in line with the previous report that isoquercitrin is a potent inhibitor of $\alpha$-glucosidase in vitro [25]. The result of the model of interaction analysis between compounds from S. polyanthum and S. cumini and the target proteins was summarized in Table 2.

\subsection{Predicting ADME}

From the result of molecular docking analysis, the chemical constituents of S. cumini and S. polyanthum, i.e., delphinidin-3-gentiobioside, quercetin, kaempferol as well as isoquercitrin are predicted to be potential as antidiabetic agents because they show a high affinity to target proteins. The pharmacokinetics (ADME) parameters of these compounds are calculated by SwissADME to assess these compounds' ability to reach the site of action after oral administration. SwissADME web tool provides many advantages, including reducing the time and cost of drug development and discovery. The ADME parameters studied are drug-likeness (based on Lipinski's Rules), gastrointestinal absorption after oral administration, bioavailability score, substrate for P-glycoprotein, and blood-brain barrier permeability [13].

The results of SwissADME analysis (table 3) reveal that delphinidin-3-gentiobioside and isoquercitrin do not meet the criteria of drug-likeness, due to the violation of Lipinski's rules (molecular weight higher than 500, hydrogen bond acceptor over 10, hydrogen bond donor over 5 , and the very low coefficient of the partition). Both compounds have a weak absorption profile; even delphinidin-3-gentiobioside is predicted as Pgp (glycoprotein substrate), which will reduce the oral absorption. Gastrointestinal absorption of quercetin and kaempferol is high. However, the bioavailability score is only 0.55 , indicating moderate permeability through the gastrointestinal capillary vessel. In the phase distribution, all the compounds are predicted not to cross the blood-brain barrier, which means it is safe to use. The results reveal that although these compounds are predicted as potential agents to treat DM, there are still some problems in pharmacokinetics profiles.

Table 3. Pharmacokinetic parameters of potential compounds

\begin{tabular}{|c|c|c|c|c|}
\hline Parameter & $\begin{array}{l}\text { Delphinidin-3- } \\
\text { gentiobioside }\end{array}$ & Quercetin & Kaempferol & Isoquercitrin \\
\hline Druglikeness & No & Yes & Yes & No \\
\hline $\begin{array}{l}\text { Gastrointestinal } \\
\text { absorption }\end{array}$ & Low & High & High & Low \\
\hline $\begin{array}{l}\text { Bioavailability } \\
\text { score }\end{array}$ & 0.17 & 0.55 & 0.55 & 0.17 \\
\hline Substrate Pgp & Yes & No & No & No \\
\hline $\begin{array}{c}\text { Blood-brain } \\
\text { barrier } \\
\text { permeability }\end{array}$ & No & No & No & No \\
\hline
\end{tabular}

\section{Conclusion}

Delphinidin-3-gentiobioside and isoquercitrin are each predicted to have good interaction with DPP-4 and $\alpha$-glucosidase. They are predicted to have poor absorption properties. Quercetin and kaempferol are each predicted to have good interactions with PTP1B and glucokinase and show excellent pharmacokinetic properties.

\section{Acknowledgment}

The authors acknowledge the Ministry of Research, Technology \& Higher Education for PDUPT funding year 2019.

\section{References}

[1] American Diabetes Association, Diagnosis and classification of diabetes mellitus, Diabetes care, 33, Supplement 1, (2010), S62-S69 https://doi.org/10.2337/dc10-S062

[2] American Diabetes Association, 2. Classification and diagnosis of diabetes: standards of medical care in diabetes-2018, Diabetes care, 41, Supplement 1, (2018), S13-S27 https://doi.org/10.2337/dc18-S002

[3] Adel S. Al-Zubairi and Eltayeb Elamin M. Eid, Molecular targets in the development of antidiabetic drugs, International Journal of Pharmacology, 6, 6, (2010), 784-795

http://dx.doi.org/10.3923/ijp.2010.784.795

[4] Prasad Patil, Surajit Mandal, Sudhir Kumar Tomar and Santosh Anand, Food protein-derived bioactive peptides in management of type 2 diabetes, European Journal of Nutrition, 54, 6, (2015), 863-880 https://doi.org/10.1007/s00394-015-0974-2

[5] Ekayanti Meiliza, Sauriasari Rani and Elya Berna, Dipeptidyl peptidase IV Inhibitory Activity of Fraction from White Tea Ethanolic Extract (Camellia sinensis (L.) Kuntze) ex vivo, Pharmacognosy Journal, 10, 1, (2018), 190-193 http://dx.doi.org/10.5530/pj.2018.1.32

[6] Jia Sun, Chao Qu, Yajun Wang, Hui Huang, Mingrui Zhang, Hongyan Li, Yejun Zhang, Yang Wang and Wei Zou, PTP1B, A Potential Target of Type 2 Diabetes Mellitus, Molecular Biology, 05, 4, (2016), 1000174 http://dx.doi.org/10.4172/2168-9547.1000174

[7] Raden Arthur Ario Lelono and Sanro Tachibana, Preliminary Studies of Indonesian Eugenia polyantha Leaf extracts as inhibitors of key enzymes for type 2 diabetes, Journal of Medical Sciences, 13, 2, (2013), 103-110 http://dx.doi.org/10.3923/jms.2013.103.110

[8] Erlena Rahim, Azlini Ismail, Muhammad Omar, Umi Rahmat and Wan Amir Nizam Wan Ahmad, GC-MS Analysis of Phytochemical Compounds in Syzygium polyanthum Leaves Extracted using UltrasoundAssisted Method, Pharmacognosy Journal, 10, (2017), 110-119 http://dx.doi.org/10.5530/pj.2018.1.20

[9] Rahul Gupta and AM Saxena, Hypoglycemic and anti-hyperglycemic activities of Syzygium cumini (Linn.) skeels whole fruit, in normal and streptozotocin-induced diabetic rats, Asian Journal of Pharmaceutical and Biological Research, 1, 3, (2011), 267-272 
[10] S Ramya, K Neethirajan and R Jayakumararaj, Profile of bioactive compounds in Syzygium cumini-a review, Journal of Pharmacy Research, 5, 8, (2012), 4548-4553

[11] Bibi Shabana and Sakata Katsumi, Current Status of Computer-Aided Drug Design for Type 2 Diabetes, Current Computer-Aided Drug Design, 12, 2, (2016), 167-177

http://dx.doi.org/10.2174/1573409912666160426120709

[12] Neema Bisht and B. K. Singh, Role of computer aided drug design in drug development and drug discovery, International Journal of Pharmaceutical Sciences and Research, 9, 4, (2018), 1405-1415 http://doi.org/10.13040/IJPSR.0975-8232.9(4).1405-15

[13] Antoine Daina, Olivier Michielin and Vincent Zoete, SwissADME: a free web tool to evaluate pharmacokinetics, drug-likeness and medicinal chemistry friendliness of small molecules, Scientific Reports, 7, 1, (2017), 42717

https://doi.org/10.1038/srep42717

[14] Sargis Dallakyan and Arthur J. Olson, SmallMolecule Library Screening by Docking with PyRx, in: J.E. Hempel, C.H. Williams, C.C. Hong (Eds.) Chemical Biology: Methods and Protocols, Springer New York, New York, NY, 2015, pp. 243-250 https://doi.org/10.1007/978-1-4939-2269-7_19

[15] Alessandro Pedretti, Luigi Villa and Giulio Vistoli, VEGA: a versatile program to convert, handle and visualize molecular structure on Windows-based PCs, Journal of Molecular Graphics and Modelling, 21, 1, (2002), 47-49 https://doi.org/10.1016/S1093-3263(02)00123-7

[16] Dassault Systèmes BIOVIA, Discovery Studio Modeling Environment, Release 2017, Dassault Systèmes, San Diego, 2016

[17] Oleg Trott and Arthur J. Olson, AutoDock Vina: Improving the speed and accuracy of docking with a new scoring function, efficient optimization, and multithreading, Journal of Computational Chemistry, 31, 2, (2010), 455-461

https://doi.org/10.1002/jcc.21334

[18] Daniel Seeliger and Bert L. de Groot, Ligand docking and binding site analysis with PyMOL and Autodock/Vina, Journal of Computer-Aided Molecular Design, 24, 5, (2010), 417-422 https://doi.org/10.1007/s10822-010-9352-6

[19] Maria Kontoyianni, Laura M. McClellan and Glenn S. Sokol, Evaluation of Docking Performance: Comparative Data on Docking Algorithms, Journal of Medicinal Chemistry, 47, 3, (2004), 558-565 https://doi.org/10.1021/jm0302997

[20]Xuan-Yu Meng, Hong-Xing Zhang, Mihaly Mezei and Meng Cui, Molecular docking: a powerful approach for structure-based drug discovery, Current computer-aided drug design, 7, 2, (2011), 146157 https://doi.org/10.2174/157340911795677602

[21] Puminan Punthasee, Adrian R. Laciak, Andrea H. Cummings, Kasi Viswanatharaju Ruddraraju, Sarah M. Lewis, Roman Hillebrand, Harkewal Singh, John J. Tanner and Kent S. Gates, Covalent Allosteric Inactivation of Protein Tyrosine Phosphatase $1 \mathrm{~B}$ (PTP1B) by an Inhibitor-Electrophile Conjugate, Biochemistry, 56, 14, (2017), 2051-2060 https://doi.org/10.1021/acs.biochem.7bo0151
[22]Carina Proença, Marisa Freitas, Daniela Ribeiro, Joana LC Sousa, Félix Carvalho, Artur MS Silva, Pedro A Fernandes and Eduarda Fernandes, Inhibition of protein tyrosine phosphatase $1 \mathrm{~B}$ by flavonoids: a structure-activity relationship study, Food and Chemical Toxicology, 111, (2018), 474-481 https://doi.org/10.1016/j.fct.2017.11.039

[23]Ronald J. Hinklin, Thomas D. Aicher, Deborah A. Anderson, Brian R. Baer, Steven A. Boyd, Kevin R. Condroski, Walter E. DeWolf, Christopher F. Kraser, Maralee McVean, Susan P. Rhodes, Hillary L. Sturgis, Walter C. Voegtli, Lance Williams and Jonathan B. Houze, Discovery of 2-Pyridylureas as Glucokinase Activators, Journal of Medicinal Chemistry, 57, 19, (2014), 8180-8186 https://doi.org/10.1021/jm501204Z

[24]Véronique Roig-Zamboni, Beatrice CobucciPonzano, Roberta Iacono, Maria Carmina Ferrara, Stanley Germany, Yves Bourne, Giancarlo Parenti, Marco Moracci and Gerlind Sulzenbacher, Structure of human lysosomal acid $\alpha$-glucosidase-a guide for the treatment of Pompe disease, Nature Communications, 8, 1, (2017), 1111 https://doi.org/10.1038/s41467-017-01263-3

[25]Yan Qin Li, Feng Chao Zhou, Fei Gao, Jun Sheng Bian and Fang Shan, Comparative Evaluation of Quercetin, Isoquercetin and Rutin as Inhibitors of $\alpha-$ Glucosidase, Journal of Agricultural and Food Chemistry, 57, 24, (2009), 11463-11468 https://doi.org/10.1021/jf903083h 